\title{
An 81-year-old patient with recent diagnosis of classic testicular seminoma
}

\author{
Sandro José Martins, ${ }^{1}$ José Carlos de Almeida, ${ }^{2}$ Vitorino Modesto dos Santos, ${ }^{3,4}$ Ana Carolina Vieira Cançado, ${ }^{4}$ \\ Giovanna Ferraz Cavalcanti, ${ }^{4}$ Kelle Regina Alves Ribeiro ${ }^{4}$ \\ ${ }^{1}$ Oncology Center, Brasília University-Hospital and Armed Forces Hospital, Brasília-DF; ${ }^{2}$ Urology Division, Armed Forces \\ Hospital, Brasília-DF; ${ }^{3}$ Medical Division, Catholic University, Brasília-DF; ${ }^{4}$ Internal Medicine Department, Armed Forces \\ Hospital, Brasília-DF, Brazil
}

\begin{abstract}
An old patient with recent diagnosis of classic seminoma is reported. The tumor of left testicle was heralded by tenderness about 30 days before medical attention and enlarged testis confirmation. There was antecedent of left testis hypotrophy treated with testosterone and a surgery for varicocele at 15 years of age. Clinical hypothesis of testicular tumor was strengthened by ultrasonography images and elevated tumor markers (lactate dehydrogenase, $\alpha$-fetoprotein, and $\beta$-hCG). Radical orchiectomy was performed and a classic seminoma (pT1pNx) was diagnosed. Active waiting was the first choice for management, but six months later a retroperitoneal mass with lymph node enlargement were found, and he underwent four sessions of carboplatin (AUC 5), bleomycin and etoposide (BEP regimen). Asymptomatic, he was referred to outpatient surveillance on Oncology. Population-based studies about frequency and outcome of early-stage testis seminoma in elderly are scarce. Case studies might contribute to the knowledge about this condition.
\end{abstract}

\section{Introduction}

Testicular cancers include germ cell tumors, cord stromal tumors, and miscellaneous germ cell/sex cord stromal tumors. ${ }^{1}$ Germ cell tumors (90-95\%) are intratubular germ cell neoplasia (ITGCN) unclassified type; seminoma (pure or classic, syncytiotrophoblastic,

Correspondence: Vitorino Modesto dos Santos, Armed Forces Hospital (HFA), Estrada do Contorno do Bosque s/n, Cruzeiro Novo, 70658-900, Brasília-DF, Brazil.

Tel.: +55.61.39662103 - Fax: +55.61.32331599.

E-mail: vitorinomodesto@gmail.com

Key words: Classic seminoma; diagnosis; elderly; testicular cancer.

Acknowledgements: the authors would like to thank Almir José Batista, the official photographer of the Armed Forces Hospital, in Brasília-DF, Brazil for the images that illustrate the present case study.

Contributions: the authors contributed equally.

Received for publication: 8 May 2015.

Accepted for publication: 31 May 2015.

This work is licensed under a Creative Commons Attribution NonCommercial 4.0 License (CC BY-NC 4.0).

CC Copyright S.J. Martins et al., 2016

Licensee PAGEPress, Italy

Italian Journal of Medicine 2016; 10:143-146

doi:10.4081/itjm.2016.603 and spermatocytic); embryonal carcinoma; yolk sac tumor; choriocarcinoma; other trophoblastic tumors; teratoma (mature, immature, or malignant); and mixed tumors. ${ }^{1-3}$ Classic seminoma represents $35 \%$ to $70 \%$ of germinative cell tumors, ${ }^{2-5}$ and is the most common type in this group. More often occurs in the third and fourth decades of life, ${ }^{2,3,5-7}$ as an asymptomatic mass and palpation of genitals is the best way to prevent underestimation of these tumors. ${ }^{8}$ On clinical evaluation, $75 \%$ of the individuals will present tumors limited to the testicle, ${ }^{5} 20 \%$ will have retroperitoneal lymph node enlargement and, in $5 \%$ of cases, blood borne implants can be found. Early-stage tumors have good outcome after radical surgery and adjuvant therapy, or active waiting. ${ }^{4}$ The aim of this report is to describe a classic seminoma in stage I diagnosed in elderly patient, evolving with retroperitoneal relapse in spite of inguinal orchiectomy. Population-based studies about testicular stage I seminoma are scarce, ${ }^{5,9}$ and case studies may contribute to better knowledge on early-stage seminoma in elderly patients.

\section{Case Report}

An 81-year-old Afro descendent man, with hypertension and hypothyroidism had tenderness in the left testicle during 30 days, before searching for a Urologist, who detected left testicle enlargement. He reported previous use of testosterone because of a left testis hypotrophy, allegedly due to late sequels of a varicocele surgery performed at his 15 years of age. 
Ultrasonography of the scrotum showed a solid mass measuring $3.0 \times 3.8 \times 3.4 \mathrm{~cm}^{3}$ (Figure 1A). In September 5,2012 , he underwent left orchiectomy and the excised testis with adnexa measured $12.0 \times 6.0 \times 4.5 \mathrm{~cm}$. The major axis of the tumor measured $4.0 \mathrm{~cm}$, and the cut surface showed a yellowish discoloration, and approximately $95 \%$ of necrotic appearance. There was invasion of the albugineal tunica, but all the other adnexal structures and surgical margins were free of malignancy. A stage I classic seminoma pT1pNx was then diagnosed by microscopy (Figure 2), and he was referred to the Clinical Oncology Division specialized evaluation and surveillance. Physical examination showed a right-handed man $1.70 \mathrm{~cm}$ tall and body mass index (BMI) of $25.2 \mathrm{~kg} / \mathrm{m}^{2}$. There was no difference between the $2^{\text {nd }} / 4^{\text {th }}$ digit ratio (respectively 7.0 and $7.3 \mathrm{~cm}$ in both hands). Tumor markers (August $30^{\text {th }}$ 2012) were lactate dehydrogenase (LDH): $201 \mathrm{IU} / \mathrm{mL}$, $\alpha$-fetoprotein (AFP): $2.73 \mathrm{IU} / \mathrm{mL}$, and $\beta$-hCG: 0.5 $\mathrm{mIU} / \mathrm{mL}$. Routine tests showed: hemoglobin $9.6 \mathrm{~g} / \mathrm{L}$, hematocrit $29.4 \%$, leukocytes $8.8 \times 10^{9} / \mathrm{L}$, platelets $341 \times 10^{9} / \mathrm{L}$, urea $22.8 \mathrm{mg} / \mathrm{dL}$, creatinine $1.2 \mathrm{mg} / \mathrm{dL}$, albumin $3.0 \mathrm{~g} / \mathrm{dL}$, thyroid-stimulating hormone 1.14 $\mathrm{mIU} / \mathrm{mL}$, free $\mathrm{T}_{4} 1.3 \mathrm{ng} / \mathrm{dL}$; the rest of biochemistry data and prostate specific antigen were normal. Physical examination was unremarkable On March 28,

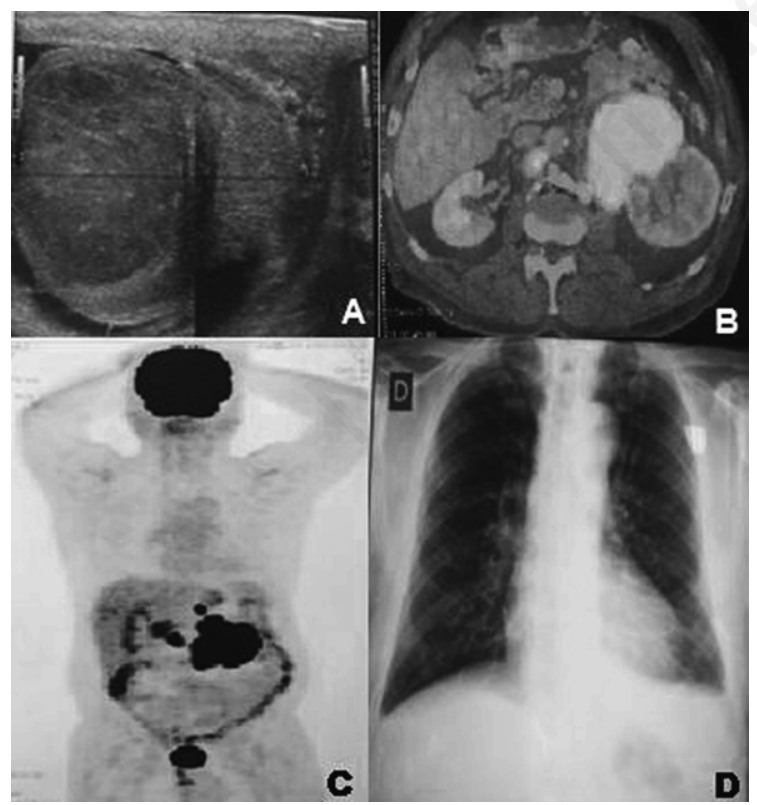

Figure 1. A) Ultrasonography image of a hypoechoic tumor measuring $3.0 \times 3.8 \times 3.4 \mathrm{~cm}^{3}$ in the left testicle; $B$ and $\mathrm{C}$ ) hypermetabolic retroperitoneal image measuring $92 \times 115 \times 69 \mathrm{~mm}$ and lymph node enlargement on the left paraaortic chain, disclosed by positron emission tomography-computed tomography postoperative control; D) radiographic image indicative of a mild inflammatory infiltrate on the left lower pulmonary lobe.
2013, a hypermetabolic retroperitoneal mass measuring $92 \times 115 \times 69 \mathrm{~mm}$ and lymph node enlargement were detected in positron emission tomographic-computed tomographic images of control (Figures 1B and 1C). With lymph node involvement indicative of tumor implants, and higher titers of LDH $(656 \mathrm{mg} / \mathrm{dL})$ and $\beta$ hCG $(1.55 \mathrm{mIU} / \mathrm{mL})$, he underwent four sessions of carboplatin (AUC 5), bleomycin and etoposide (BEP regimen). On the third day of treatment, a chest X-ray showed discrete inflammatory infiltrate on the lower lobe of left lung (Figure 1D). Successful resolution of the pulmonary changes was achieved by intravenous administration of cefepime. Comparative titers of tumor markers from August 2012 to March 2013 are shown in Table 1. Asymptomatic, he was referred to outpatient follow-up at Clinical Oncology Division.

\section{Discussion}

The patient herein described had a classic seminoma which was diagnosed at his 81 years of age. The patient is a right-handed Brazilian man with a normal BMI, without antecedent of cryptorchidism or trauma, nor history of testicular cancer in his close relatives. He was born at term with a normal birth weight, and his mother was a non-smoker young woman. Moreover, there were no significant differences between comparative lengths of the second and the fourth hand digits. ${ }^{10}$ Of note was the use of testosterone for two

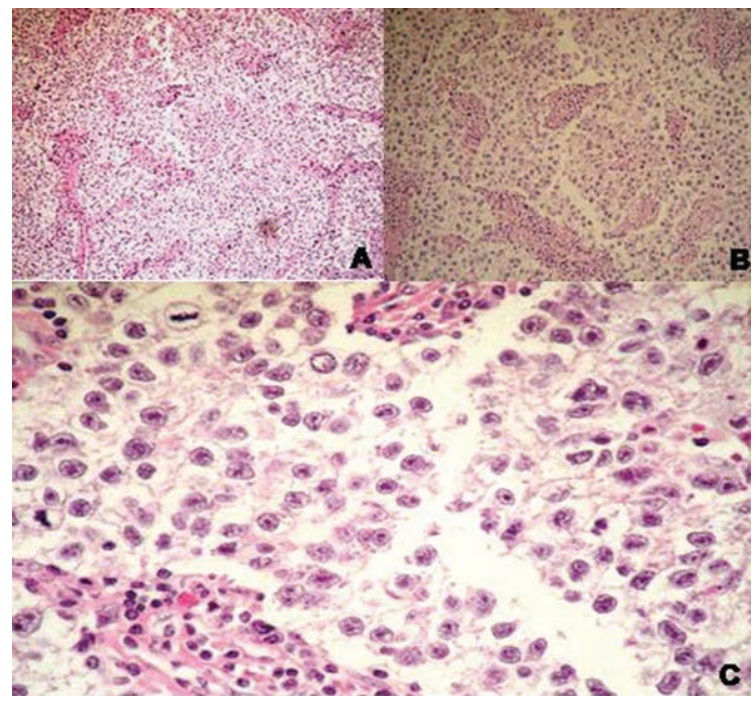

Figure 2. A-C) Histopathology of classic seminoma - trabecular and nested proliferation of large cells with abundant pale to granular cytoplasm, large nuclei with coarse chromatin and conspicuous nucleoli, and a high mitotic rate. The supporting stroma shows lymphocytic infiltrates (hematoxylin and eosin, original magnifications: $\times 100, \times 200$ and $\times 400)$. 
Table 1. Laboratory data of an 81-year-old man with recent diagnosis of classical seminoma.

\begin{tabular}{lccc}
\hline Tumor markers & August 20 $^{\text {th }} \mathbf{2 0 1 2}$ & August 30 $^{\text {th }} \mathbf{2 0 1 2}$ & March 26 $^{\text {th }} \mathbf{2 0 1 3}$ \\
\hline$\alpha$-fetoprotein $(\mathrm{IU} / \mathrm{mL})$ & 1.70 & 2.73 & 2.95 \\
\hline $\mathrm{LDH}(\mathrm{mg} / \mathrm{dL})$ & 26.9 & 201.0 & 656.0 \\
\hline$\beta$-hCG $(\mathrm{mIU} / \mathrm{mL})$ & $<0.50$ & $<0.50$ & 1.55 \\
\hline Total PSA $(\mathrm{ng} / \mathrm{mL})$ & 2.60 & n.a. & 2.24 \\
\hline
\end{tabular}

LDH, lactate dehydrogenase; PSA, prostate specific antigen. Date of orchiectomy: September $5^{\text {th }}$ 2012. n.a., not available data.

decades, allegedly to correct a left testis hypotrophy. Testosterone itself seems not involved in the etiology or pathogenesis of testicular tumors, and the incidence of ITGCN is positively related to atrophic testis and negatively with ageing. ${ }^{11}$ As often occurs, his testicular tumor developed unsuspected for long time in a testis with atrophy. Ultimately, a local tenderness called for the patient attention and he was seen by a urologist, who established the clinical hypothesis and performed the immediate radical left orchiectomy, after seeing the typical ultrasonography images from testis and the levels of tumor markers. Furthermore, the gross and microscopic tumor features were typical of classic seminoma. ${ }^{1,3}$

Worthy of note, classic testicular seminomas and non-seminomas are not common in people older than 60 years, while spermatocytic seminoma, malignant Leydig cell tumors and lymphomas, in addition to paratesticular sarcomas are more commonly diagnosed among elderly patients. ${ }^{6}$ Testicular tumors correspond to $1 \%$ to $1.5 \%$ of all solid tumors in man, ${ }^{1}$ and are most common in individuals under 40 years of age. ${ }^{1-3,5-7}$ Testicular germinative cell tumors can give origin to ipsilateral metastases for retroperitoneal lymph node chains, and metastases from left sided seminomas are usually found in the left paraaortic chain. ${ }^{3}$ Interaortocaval and thoracic lymph nodes are usually affected in the higher stages of tumors. ${ }^{3}$

Tumor markers like AFP, LDH, and $\beta$-hCG, are useful to confirm the diagnosis of pure seminoma as well for the risk assessment. ${ }^{1,3}$ Inguinal orchiectomy followed by radiotherapy or watchful waiting may achieve cure in over than $99 \%$ of patients with seminoma in early-stage. ${ }^{5}$ Relapses may occur in $15 \%$ to $20 \%$ of stage I seminoma submitted to surgery alone, due to subclinical retroperitoneal metastases, which can be effectively controlled by chemotherapy. ${ }^{1}$ Combination of bleomycin, etoposide and cisplatin is recommended for low risk patients, with excellent results and very scarce toxicity. ${ }^{1}$ Less toxic, isolated carboplatin is successfully used for patients with seminoma in early stages. ${ }^{1}$

Epidemiologic risk factors include cryptorchidism, Klinefelter syndrome, testicular cancer in first-grade relatives, contralateral tumor, testicular intraepithelial neoplasia, and infertility. ${ }^{1,2,12,13}$ Recent findings of a preliminary study have indicated that occurrence of seminoma is positively associated with tallness and inversely related with body mass index. ${ }^{12}$ Moreover, birth weight and maternal age at birth are independent risk factors for this tumor; ${ }^{13}$ otherwise, the role of trauma is controversial and some studies did not find this association. ${ }^{2,8}$ Actual consensus is that seminoma and non-seminoma of testis share the similar risk factors. ${ }^{13}$ Both subtypes are derived from gonocytes, which migrate to the gonads at 5 to 6 weeks of pregnancy and are associated with testicular intraepithelial neoplasia, a premalignant entity. ${ }^{13}$

Hypotheses of testicular cancer often depend on clinical and ultrasound findings. ${ }^{1,4}$ Echography can detect testicular masses with near $100 \%$ of sensibility, and seminomas appear as well-defined homogeneous hypoechoic masses. ${ }^{4}$ Final diagnosis is based on microscopic data because more than one cell type can be found in over than $50 \%$ of the germ cell tumors. ${ }^{3}$

\section{Conclusions}

Classic seminoma is the most usual histopathology type of testicular malignancy, and its prevalence in the elderly group of patients is lower than among the younger groups. Worthy of note is the painless development of this tumor, which follows unnoticed for long periods, before accurate examination of the scrotum can detect the unsuspected malignancy. The most indicative manifestation is asymptomatic unilateral enlargement of affected testis. Better outcomes are associated with early diagnosis and prompt treatment of this rare tumor. The authors believe that case reports enhance the suspicion index about seminoma in elderly.

\section{References}

1. Albers P, Albrecht W, Algabac F, et al. EAU guidelines on testicular cancer: 2011 update. Actas Urol Esp 2012; 36:127-45.

2. Darabi MR, Barzegarnejad A. Bilateral cryptorchid malignancy with persistent Mullerian duct. Urol J 2004; $1: 131-2$. 
3. Sesterhenn IA, Davis CJ. Pathology of germ cell tumors of the testis. Cancer Control 2004;11:374-87.

4. García Bocanegra I, Márquez Moreno AJ, Julve Villalta E, et al. Seminoma and teratocarcinoma: synchronic unitesticular presentation as independent nodules with different histologies? Ultrasound characteristics. Arch Esp Urol 2007;60:582-5.

5. Khader J, Salem A, Abuodeh Y, et al. Stage I seminoma: treatment outcome at King Hussein Cancer Center in Jordan. BMC Urol 2012;12:10.

6. Gigantino V, La Mantia E, Franco R, et al. Testicular and testicular adnexa tumors in the elderly. Anticancer Drugs 2013;24:228-36.

7. Ruf CG, Isbarn H, Wagner W, et al. Changes in epidemiologic features of testicular germ cell cancer: Age at diagnosis and relative frequency of seminoma are constantly and significantly increasing. Urol Oncol 2013; 32:33.e1-6.

8. Polito M, Catanzariti F, Quaresima L, et al. Association between trauma and cancer of the testis: the importance of self-palpation of the testis for the early detection: two case reports. Urologia 2012;79:S116-20.

9. Beard CJ, Travis LB, Chen MH, et al. Outcomes in stage I testicular seminoma: A population-based study of 9193 patients. Cancer 2013;119:2771-7.

10. Trabert B, Graubard BI, Erickson RL, et al. Second to forth digit ratio, handedness and testicular germ cell tumors. Early Hum Dev 2013;89:463-6.

11. Buchler T, Freeman A, Harland S. Contralateral intratubular germ cell neoplasia in a patient with testicular cancer, Nat Clin Pract Urol 2008;3:83-91.

12. Bray F, Richiardi L, Ekbom A, et al. Do testicular seminoma and nonseminoma share the same etiology? Evidence from an age-period-cohort analysis of incidence trends in eight European countries. Cancer Epidemiol Biomarkers Prev 2006;15:652-8.

13. Giannandrea F, Paoli D, Lombardo F, et al. Case-control study of antropometric measures and testicular cancer risk. Front Endocrinol (Lausanne) 2012;3:144. 